\title{
Surface Preparation of Powder Metallurgical Tool Steels by Means of Wire Electrical Discharge Machining
}

\begin{abstract}
SEPEHR HATAMI, MEHRDAD SHAHABI-NAVID, and LARS NYBORG
The surface of two types of powder metallurgical (PM) tool steels (i.e., with and without nitrogen) was prepared using wire electrical discharge machining (WEDM). From each grade of tool steel, seven surfaces corresponding to one to seven passes of WEDM were prepared. The WEDM process was carried out using a brass wire as electrode and deionized water as dielectric. After each WEDM pass the surface of the tool steels was thoroughly examined. Surface residual stresses were measured by the X-ray diffraction (XRD) technique. The measured stresses were found to be of tensile nature. The surface roughness of the WEDM specimens was measured using interference microscopy. The surface roughness as well as the residual stress measurements indicated an insignificant improvement of these parameters after four passes of WEDM. In addition, the formed recast layer was characterized by means of scanning electron microscopy (SEM), XRD, and X-ray photoelectron spectroscopy (XPS). The characterization investigation clearly shows diffusion of copper and zinc from the wire electrode into the work material, even after the final WEDM step. Finally, the importance of eliminating excessive WEDM steps is thoroughly discussed.
\end{abstract}

DOI: $10.1007 / \mathrm{s} 11661-012-1137-1$

(C) The Minerals, Metals \& Materials Society and ASM International 2012

\section{INTRODUCTION}

POWDER metallurgical (PM) tool steels are a new and evolving category of tool steels, exhibiting excellent tribological properties and superior mechanical properties as compared to their cast counterparts. In contrast to conventional ingot cast tool steels (such as AISI D2), PM tool steels contain homogeneously distributed fine carbides and nitrides. This microstructure is achieved by hot isostatic pressing prealloyed gas atomized powder to full density. ${ }^{[1]}$ Due to their good wear resistance and reasonable toughness, PM tool steels are increasingly finding applications in the cold forming industries (e.g., sheet metal forming, deep drawing, and powder metallurgy) and are typically used as die and punch material. ${ }^{[2-6]}$

Whether it is sheet metal forming, deep drawing, or metal powder compaction, a low friction die surface is invariably a necessity as it will reduce the risk of premature failure. Furthermore, the surface condition of the final component (i.e., work material) is directly related to that of the die. Therefore, in order to enhance the performance of the die and the surface quality of the final product, correct surface preparation of the forming

SEPEHR HATAMI, formerly Postdoctoral Researcher, Department of Materials and Manufacturing Technology, Chalmers University of Technology, 41296 Gothenburg, Sweden, is now R\&D Engineer, AB SKF, 41550 Gothenburg, Sweden. Contact e-mail: hatami@alumni.chalmers.se MEHRDAD SHAHABI-NAVID, formerly Master's Student, Department of Materials and Manufacturing Technology, Chalmers University of Technology, is now PhD Student, Department of Environmental Inorganic Chemistry, Chalmers University of Technology. LARS NYBORG, Professor and Head of the Department, is with the Department of Materials and Manufacturing Technology, Chalmers University of Technology.

Manuscript submitted June 23, 2011.

Article published online May 26, 2012 die is essential and it is usually performed differently by different manufacturers.

In metal forming operations where high loads are applied and components with intricate geometries are to be manufactured (e.g., powder metallurgy), high strength and hardness die materials are required. A means of creating intricate cavities in high strength forming dies is by application of electrical discharge machining (EDM). In EDM, the material is removed by electric sparks (i.e., electrical discharge) that takes place between the electrode and the work material, inside a dielectric liquid. The energy within the spark is enormous, $10^{17} \mathrm{~W} / \mathrm{m}^{2}$, and the local temperature is reported to reach up to $20,000 \mathrm{~K} \cdot{ }^{[7]}$ Therefore, the spark can melt and even vaporize the work material and the electrode. When the current stops and the spark ceases (the socalled "off-time"), the machined debris and the molten material are flushed away by new deionized dielectric fluid. Despite the fact that the machined surfaces are flushed by the dielectric medium, it has been reported that only $15 \mathrm{pct}$ (or less) of the molten material is removed during the flushing stage and the rest is resolidified (or recast) on the machined surface. ${ }^{[8]}$ The recast layer is also referred to as the white layer due to the fact that commonly it does not etch; hence, under the optical microscope, it appears as a white layer.

It is well known that the recast layer usually contains surface cracks. ${ }^{[7-15]}$ These cracks are microscopic ${ }^{[12]}$ and are created as a by-product of the tensile surface stresses that exceed the ultimate tensile strength of the material within the recast layer. ${ }^{[10,15,16]}$ The general cause of tensile stresses on the surface is related to the large thermal contraction of the surface (exposed to the flushing medium) relative to the unaffected bulk of the material, which stretches the recast layer upon 
cooling. ${ }^{[10,15]}$ The presence of cracks combined with high tensile stresses at the surface of the tool can dramatically lower the mechanical properties of the machined material, particularly the fatigue properties. ${ }^{[8,10,11]}$ In ferrous materials, the hardness of the recast layer is reported to be much higher than that of the bulk, ${ }^{[15,17,18]}$ while beneath the recast layer, a heat-affected zone is commonly found, exhibiting a hardness less than the matrix. ${ }^{[8]}$

To nullify the adverse effect of surface cracks on the performance of electrical discharge machined surfaces, particularly in applications where high loads and tight tolerances are required, normally, the recast layer is removed by an additional postprocessing treatment, ${ }^{[8]}$ such as conventional machining, chemical etching, ${ }^{[15]}$ or shot peening. Alternatively, the recast layer can be removed by multicutting passes of wire electrical discharge machining (WEDM) ${ }^{[8]}$ It is believed that by this machining procedure (i.e., multicutting the surface by WEDM), a tool surface with appropriate surface integrity and negligible amount of recast layer can be obtained; thereby, surface defects associated with the recast layer can be eliminated.

In this study, the surface of two newly developed PM tool steels, which are increasingly finding applications in cold metal forming operations, were prepared by multiple-cutting passes of WEDM. The surface integrity of both tool steel grades was carefully examined, and aspects such as recast layer formation, residual stress development, and surface roughness were investigated after each WEDM pass. The aim of this investigation was to evaluate the machinability response of the investigated PM tool steels to a multicutting WEDM procedure. Furthermore, the outcome of this article can aid tool makers toward a more efficient and economic usage of WEDM as a means of surface preparation of PM tool steels.

\section{EXPERIMENTAL}

The present study deals with two types of powder metallurgical cold work tool steels: so-called Vancron 40 and Vanadis 10. The chemical composition and the content of hard particles of both tool steels are given in Table I. The hard phase particle content was calculated using thermodynamic simulation software (i.e., THERMO-CALC). ${ }^{[19]}$

In order to acquire adequate toughness as well as hardness, both tool steels were heat treated according to the cycles indicated in Table II. After being heat treated, the investigated alloys showed a similar hardness of 62 HRC.

From each grade of tool steel, seven surfaces were prepared corresponding to one to seven cuts of WEDM. The specimens $\left(12 \times 20 \times 20 \mathrm{~mm}^{3}\right)$ were machined out from a bar $\left(120 \times 20 \times 20 \mathrm{~mm}^{3}\right)$. The WEDM was carried out by means of a standard machine of type Sodick AQ537L (Auran Technologies AB, Nysätravägen 2, Nacka, Sweden). The electrode was a brass wire with a diameter of $0.25 \mathrm{~mm}$, which was coated with zinc. The wire was positively polarized during all seven cutting passes. Deionized water was used as the dielectric fluid for all seven cutting passes. Specimens machined with six WEDM passes were not manufactured and, thus, are not included in this investigation.

Surface topography of the machined specimens was examined by means of a field emission gun scanning electron microscope (LEO 1550, Gemini Instrument, Zeiss, Oberkochen, Germany) as well as interference microscopy (RTS Plus, WYKO Corporation, Tuscon, AZ). In addition, the recast layer was investigated using a scanning electron microscope combined with a backscattered detector. A X-ray diffraction (XRD) technique was carried out by means of a Bruker D8 Advance instrument (Bruker AXS Nordic AB, Vallgatan 5, Solna, Sweden) with $\mathrm{Cr} K_{\alpha}$ radiation $(\lambda=2.2897 \AA)$. For phase identification, the diffraction patterns were analyzed with reference to the International Center for Diffraction Data (ICDD). After every WEDM pass, the recast layer was analyzed by means of a PHI 5500 X-ray photoelectron spectroscopy (XPS) instrument with a monochromatized Al $K_{\alpha}$ source.

Surface residual stresses of the machined specimens were measured by means of an X-ray stress analyzer instrument (XSTRESS 3000 G2/G2R, Stresstech Oy, Rönninge, Sweden) and based on the standard $\sin ^{2} \Psi$ method. ${ }^{[20]}$ The X-ray source was $\operatorname{Cr} K_{\alpha}(\lambda=2.2897 \AA)$, and the two theta $(2 \theta)$ positions of the $\{211\}$ planes of the ferrite phase were analyzed. Measurements were performed with five tilt angles (from $\psi=-45 \mathrm{deg}$ to $\psi=+45 \mathrm{deg})$, an exposure time of 20 seconds at each

Table I. Chemical Composition (Weight Percent) and Hard Phase Particle Content (Volume Percent) of the Investigated PM Tool Steels ${ }^{[6]}$

\begin{tabular}{lcccccccccccccc}
\hline Steel Grade & $\mathrm{Fe}$ & $\mathrm{C}$ & $\mathrm{N}$ & $\mathrm{Cr}$ & $\mathrm{Mo}$ & $\mathrm{W}$ & $\mathrm{Si}$ & $\mathrm{Mn}$ & $\mathrm{V}$ & $\mathrm{MN}$ & $\mathrm{MC}$ & $\mathrm{M}_{6} \mathrm{C}$ & $\mathrm{M}_{7} \mathrm{C}_{3}$ & Total \\
\hline Vanadis 10 & bal & 2.9 & 0.1 & 8.0 & 1.5 & - & 0.5 & 0.5 & 9.8 & - & 16 & - & 7 & 23 \\
Vancron 40 & bal & 1.1 & 1.8 & 4.5 & 3.2 & 3.7 & 0.5 & 0.4 & 8.5 & 14 & - & 5 & - & 19 \\
\hline
\end{tabular}

Table II. Heat Treatment Cycles of the PM Tool Steels

\begin{tabular}{lccc}
\hline Steel Grade & Austenitization Temperature and Time & Tempering Temperature Time & Hardness $($ HRC) \\
\hline Vanadis 10 & $1293 \mathrm{~K}\left(1020^{\circ} \mathrm{C}\right) / 0.5 \mathrm{~h}$ & $798 \mathrm{~K}\left(525^{\circ} \mathrm{C}\right) / 2 \times 2 \mathrm{~h}$ & 62 \\
Vancron 40 & $1293 \mathrm{~K}\left(1020^{\circ} \mathrm{C}\right) / 0.5 \mathrm{~h}$ & $833 \mathrm{~K}\left(560^{\circ} \mathrm{C}\right) / 3 \times 1 \mathrm{~h}$ & 62 \\
\hline
\end{tabular}



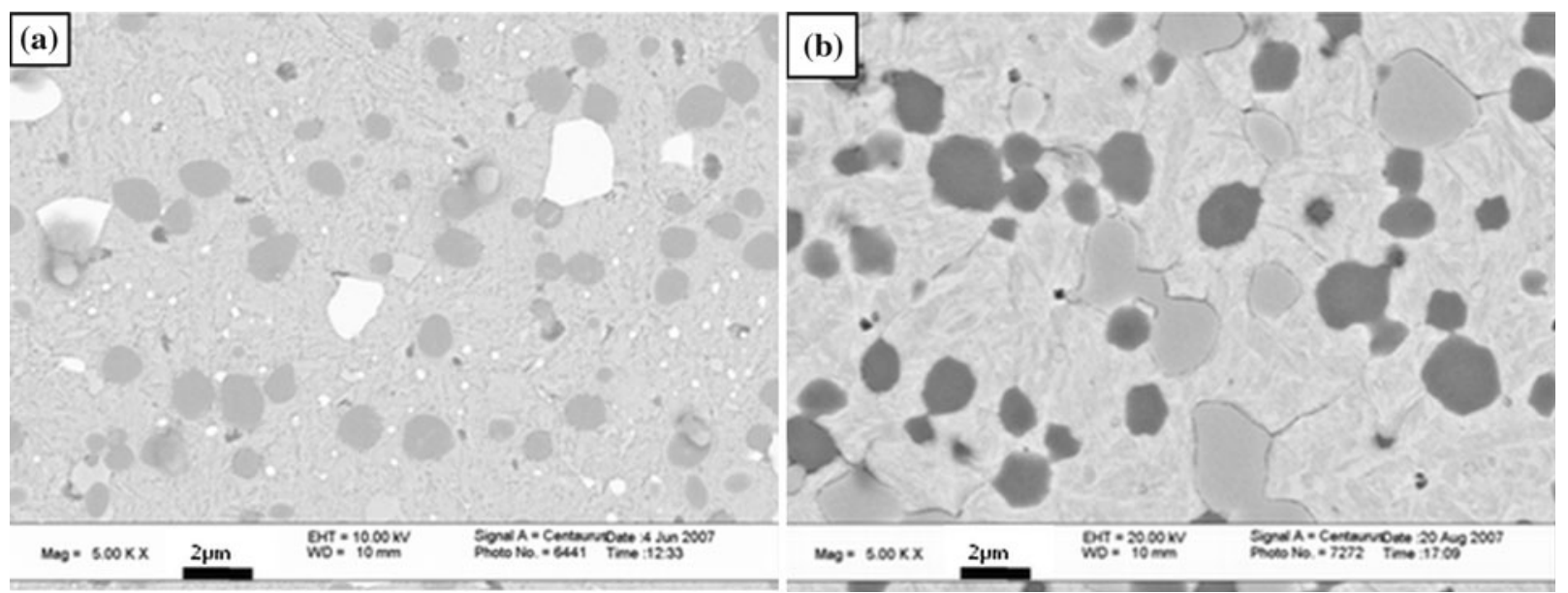

Fig. 1-SEM backscattered images of (a) Vancron 40 and (b) Vanadis 10 in as-polished condition. Images taken at 5000 times magnification.

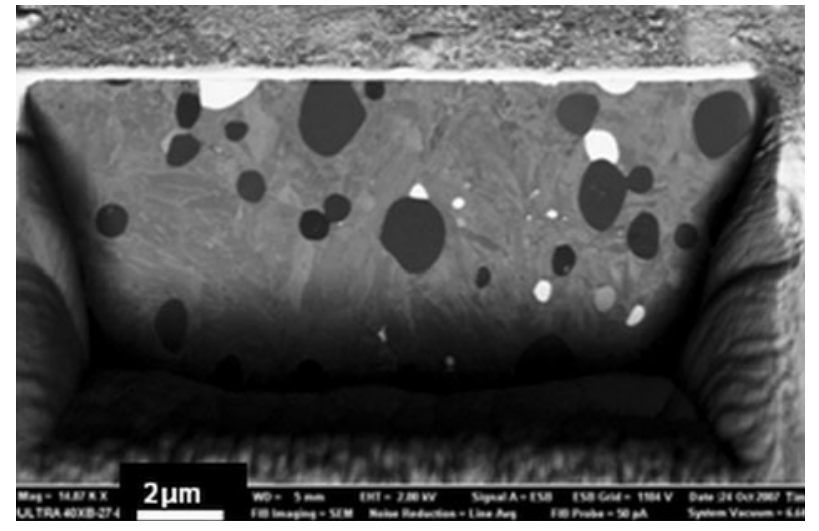

Fig. 2- Cross section of Vancron 40 prepared by FIB and imaged using SEM and backscattered detector.

angle, and along two perpendicular directions $(\varphi=$ $0 \mathrm{deg}$ and $\varphi=90 \mathrm{deg}$ ). In all measurements, a 2-mmdiameter collimator was used. The stress conversion was carried out using an elastic modulus value of $E=$ $209 \mathrm{GPa}$ and Poisson's ratio of $v=0.3$. Each test was repeated at least 3 times and an average was calculated.

\section{RESULTS}

\section{A. Microstructure of the Tool Materials}

The microstructures of the investigated tool steels after heat treatment (according to Table II) are illustrated in Figure 1. The images are taken with scanning electron microscopy (SEM) and using the backscatter detector.

The hard particles shown in Figure 1 are in the range 1 to $2 \mu \mathrm{m}$ and are homogeneously distributed. As illustrated in Figure 1, it is clear that Vancron 40 and Vanadis 10 contain two separate families of precipitates. Combining the results from thermodynamic modeling ${ }^{[6,19]}$ (Table I) with previous characterization studies ${ }^{[2]}$ of these alloys by means of XRD as well as SEM-energy dispersive spectroscopy, it can be inferred that the dark particles in Vancron 40 grade
(Figure 1(a)) are vanadium-rich carbonitrides with a chemistry close to $\mathrm{MN}^{[2,19]}$ and the light particles correspond to carbides of type $\mathrm{M}_{6} \mathrm{C}$. The $\mathrm{M}_{6} \mathrm{C}$ carbides consist of $\mathrm{W}, \mathrm{Mo}$, and Fe ${ }^{[2,4]}$ On the other hand, the precipitates in Vanadis 10 steel are $\mathbf{M}_{7} \mathrm{C}_{3}$ (light gray in Figure 1(b)) and vanadium-rich $\mathrm{MC}$ carbides (dark gray in Figure 1(b)). The $\mathrm{M}_{7} \mathrm{C}_{3}$ carbides are rich in $\mathrm{Cr}$ and $\mathrm{Fe} .^{[2,4]}$

By means of in-situ scanning electron microscopyfocused ion beam (SEM-FIB), cross sections of the Vancron 40 tool steel were etched and imaged (Figure 2). By stacking numerous cross-sectional images taken within short time intervals, a movie was prepared, with which the three-dimensional morphology of the particles was determined. From the in-situ SEM-FIB characterization, it was found that the vanadium-rich carbonitrides are more elliptical, whereas the $\mathrm{M}_{6} \mathrm{C}$ particles have the shape of a polyhedron. Similarly, in the Vanadis 10 material, the MC vanadium carbides are elliptical and the $\mathrm{M}_{7} \mathrm{C}_{3}$ carbides are polyhedron.

The primary precipitates in Vancron 40 and Vanadis 10 grades are the nitrogen-rich $\mathrm{V}(\mathrm{C}, \mathrm{N})$ and $\mathrm{VC}$ particles, respectively. The solubility product of chromium and molybdenum carbides (in austenite) is typically higher than that of vanadium carbides (VC) and nitrides $(\mathrm{VN}){ }^{[21]}$ thus, upon solidification, the vanadium-rich hard particles will precipitate first and they will serve as nucleation sites for $\mathrm{M}_{7} \mathrm{C}_{3}$ and $\mathrm{M}_{6} \mathrm{C}$ particles. This can be seen in the SEM-FIB images illustrated in Figure 2, where the $\mathrm{M}_{6} \mathrm{C}$ particles (seen as white) have nucleated on the $\mathrm{VN}$ particles (appearing as dark).

\section{B. Surface Topography and Recast Layer Formation}

To evaluate how each WEDM pass affects the surface conditions of the investigated tool steels, surface topography measurements were carried out using interference microscopy. The results are shown in Figure 3. The measurements were repeated 3 times and the average was calculated. As illustrated in Figure 3(a), a considerable decrease in surface roughness is achieved by the first three passes of WEDM; however, after the third pass, no significant reduction of surface roughness can be detected. In addition to the $\mathrm{Ra}$ value (i.e., average 


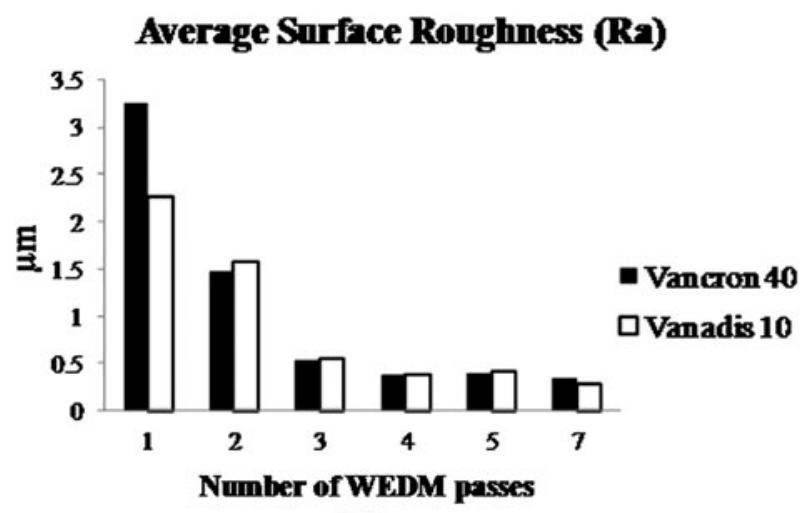

(a)

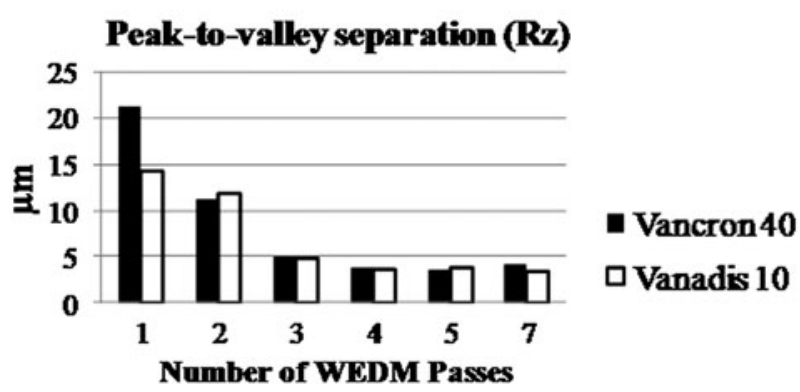

(b)

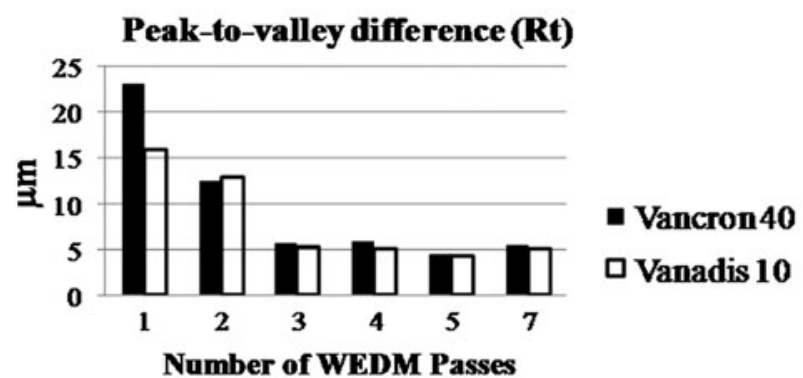

(c)

Fig. 3-Surface topography measurements of the investigated materials by means of interference microscopy.

surface roughness), $\mathrm{Rz}$ (i.e., the average of the ten greatest peak-to-valley separations) and Rt (i.e., peakto-valley difference) were also measured and similar trends were observed (Figures 3(b) and (c), respectively). Furthermore, surface topography of the machined samples was examined after every WEDM pass and by using SEM. Figure 4 shows the surface condition of the investigated materials after the first, fourth, and seventh passes of WEDM.

A very rough surface with deep craters, voids, and remnants of resolidified molten metal is seen after the first WEDM step (Figure 4). The surface of the samples after the fourth pass is clearly smoother than after the first pass; however, as compared to the final surface (i.e., after the seventh pass), no significant roughness reduction can be observed. Moreover, surface microcracks were found on the machined surfaces, especially after the first and second WEDM passes. A few examples of such microcracks were indicated by arrows in Figures 4(a) and (d).
A more thorough analysis of the number and the length of microcracks was performed using SEM micrographs. In order to count the number of surface cracks, from each machined surface, ten SEM images were taken at random positions. The SEM micrographs were taken at a fixed magnification of 5000 times, and the average number of cracks was calculated. The results are illustrated in Figure 5. As shown in the chart, it is clear that Vancron 40 has a higher number of surface cracks as compared to Vanadis 10. The lengths of the surface cracks were measured by means of imaging software (Zeiss AxioVision) on ten random SEM images, which were taken at a fixed magnification of 5000 times. As shown in Figure 6, the length of the surface cracks decreases with the increasing number of machining steps. From Figure 6, it can be inferred that the cracks formed on Vancron 40 steel grade are slightly longer than those on Vanadis 10 material.

In order to determine the thickness of the recast layer, cross sections of the machined specimens were investigated by means of SEM (Figure 7). As shown in Figure 7, after the first and second WEDM steps, a recast layer with an approximate thickness of 1 to $2 \mu \mathrm{m}$ is formed on the surface of both tool steels. However, from the third pass onward, the recast layer is completely removed. Furthermore, after the first and second WEDM passes, the surface profile is very rough, whereas from the third pass and onward, the surface becomes considerably smoother; hence, the profile appears flat. In both tool steel grades, cracks propagating through the recast layer were frequently found after the first machining step (Figure 8). Such cracks were seldom seen after the second WEDM pass and were almost completely eliminated after the third machining pass.

As shown in Figure 8, secondary carbides (i.e., $\mathrm{M}_{6} \mathrm{C}$ in Vancron 40 and $\mathrm{M}_{7} \mathrm{C}_{3}$ in Vanadis 10) were not observed within the recast layer. $\mathrm{M}_{6} \mathrm{C}$ particles are visualized as white (Figure $8(\mathrm{a})$ ) and $\mathbf{M}_{7} \mathbf{C}_{3}$ appear as light gray (Figure 8(b)). In addition, the primary precipitates (i.e., VN in Vancron 40 and VC in Vanadis 10) seem to be fewer in number within the recast layer as compared to the bulk.

\section{Surface Residual Stresses}

The measured surface residual stresses of all machined samples were found to be of tensile nature. Variation of residual stresses corresponding to different WEDM passes is shown in Figure 9. The stresses were measured along transversal and longitudinal directions (i.e., $\Phi=0 \mathrm{deg}$ and $\Phi=90 \mathrm{deg}$ ) and were found to be approximately similar for the investigated tool steels (Figure 9). The surface residual stresses decrease from $\sim 600 \mathrm{MPa}$ after the first WEDM pass to a minimum of $\sim 300 \mathrm{MPa}$ after the fourth step. As illustrated in Figure 9, additional machining passes increase the residual stresses, and a stress level of 400 to $450 \mathrm{MPa}$ is created after the seventh machining step.

\section{XRD Analyses}

The XRD measurements were carried out on all the machined surfaces (from pass 1 to pass 7 ) as well as the 

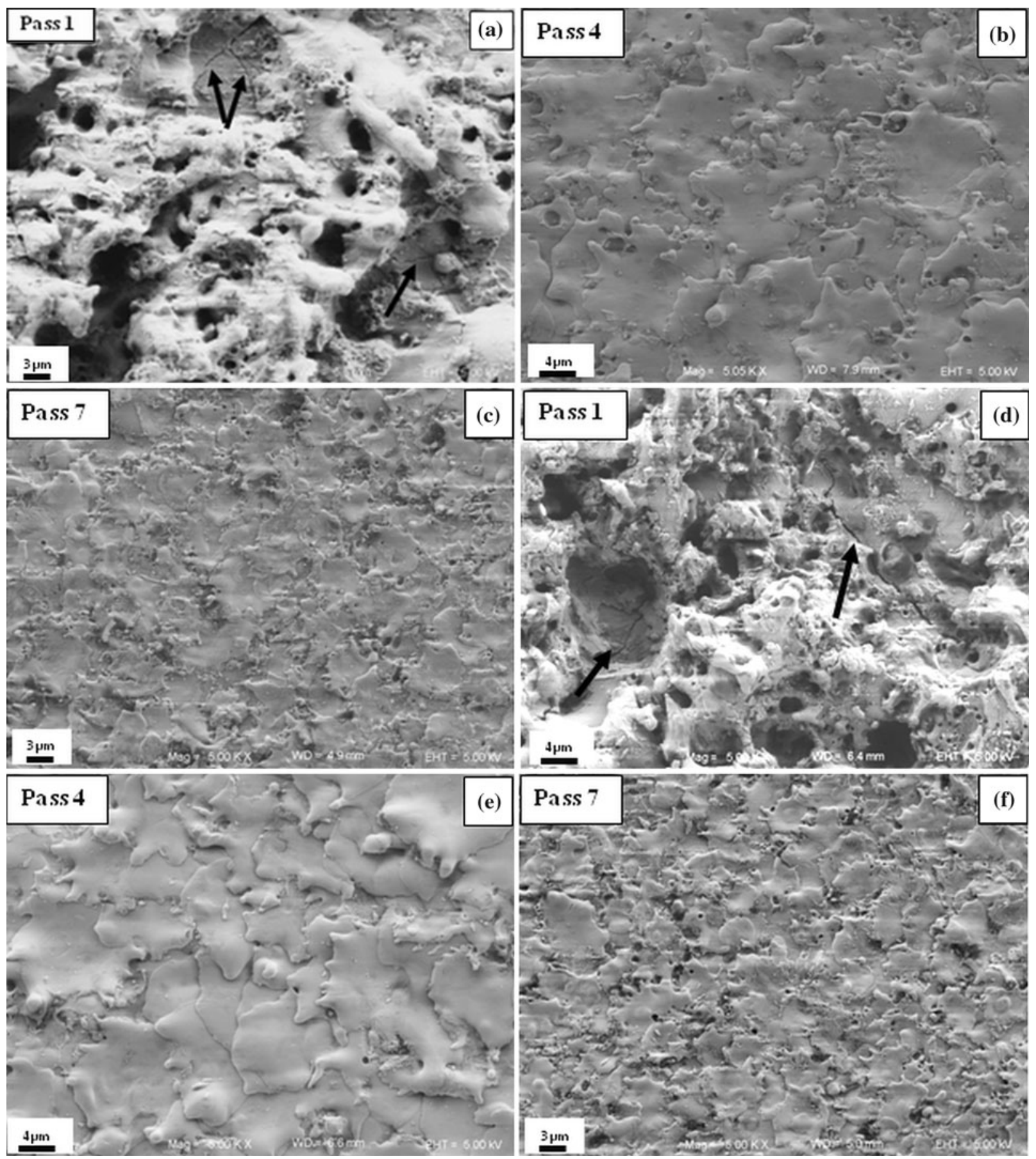

Fig. 4-SEM images from the surface of machined specimens. (a) through (c) Vancron 40 and (d) through $(f)$ Vanadis 10. Arrows indicate surface microcracks in (a) and (d). All images have been taken at 5000 times magnification.

unmachined (so-called bulk) material. The XRD patterns are stacked and are shown in Figure 10. While distinct peaks corresponding to carbides and nitrides can be seen in the XRD spectra of the bulk material (in both tool steels), after the first and second WEDM passes, these peaks are either very weak or no longer present. Furthermore, additional peaks are seen on the spectra of the machined specimens, which are not found in the bulk material. The XRD characterization suggests that these additional peaks are related to a $\mathrm{Cu}_{x} \mathrm{Zn}_{y}$ phase formed during the WEDM process. The reference peak positions for $\mathrm{Cu}_{0.64} \mathrm{Zn}_{0.36}$ are at $2 \theta=64.95,76.57$, and $122.44 \mathrm{deg}$ (PDF Card Number 50-1333). These angles are close to the peaks observed in the spectra shown in Figure 10; hence, the presence of a phase containing $\mathrm{Cu}$ and $\mathrm{Zn}$ but with a different stochiometry than that of the reference can be inferred. This will be further discussed in Sections III-E and III-F. 


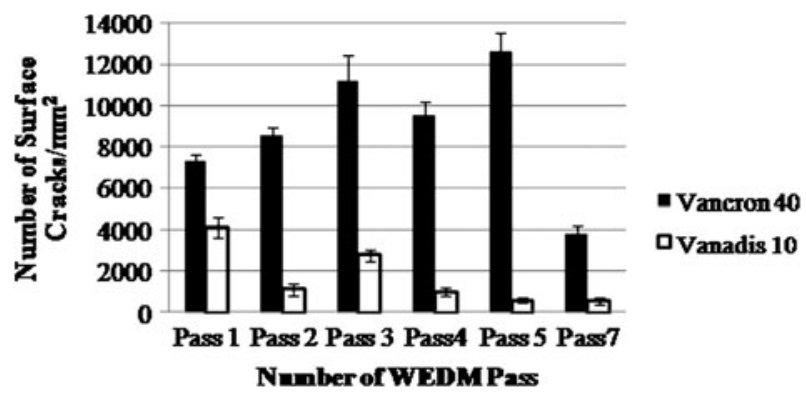

Fig. 5-Average number of surface cracks per square millimeter, after each pass of WEDM. Error bars indicate the standard error of the mean.

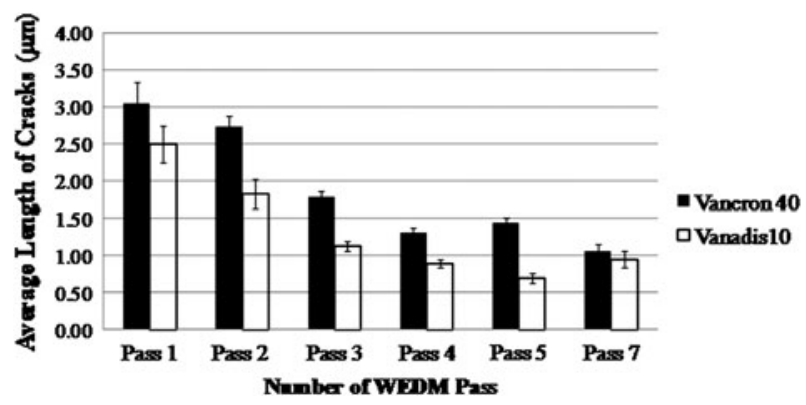

Fig. 6-Average length of surface cracks after each pass of WEDM. Error bars indicate the standard error of the mean.
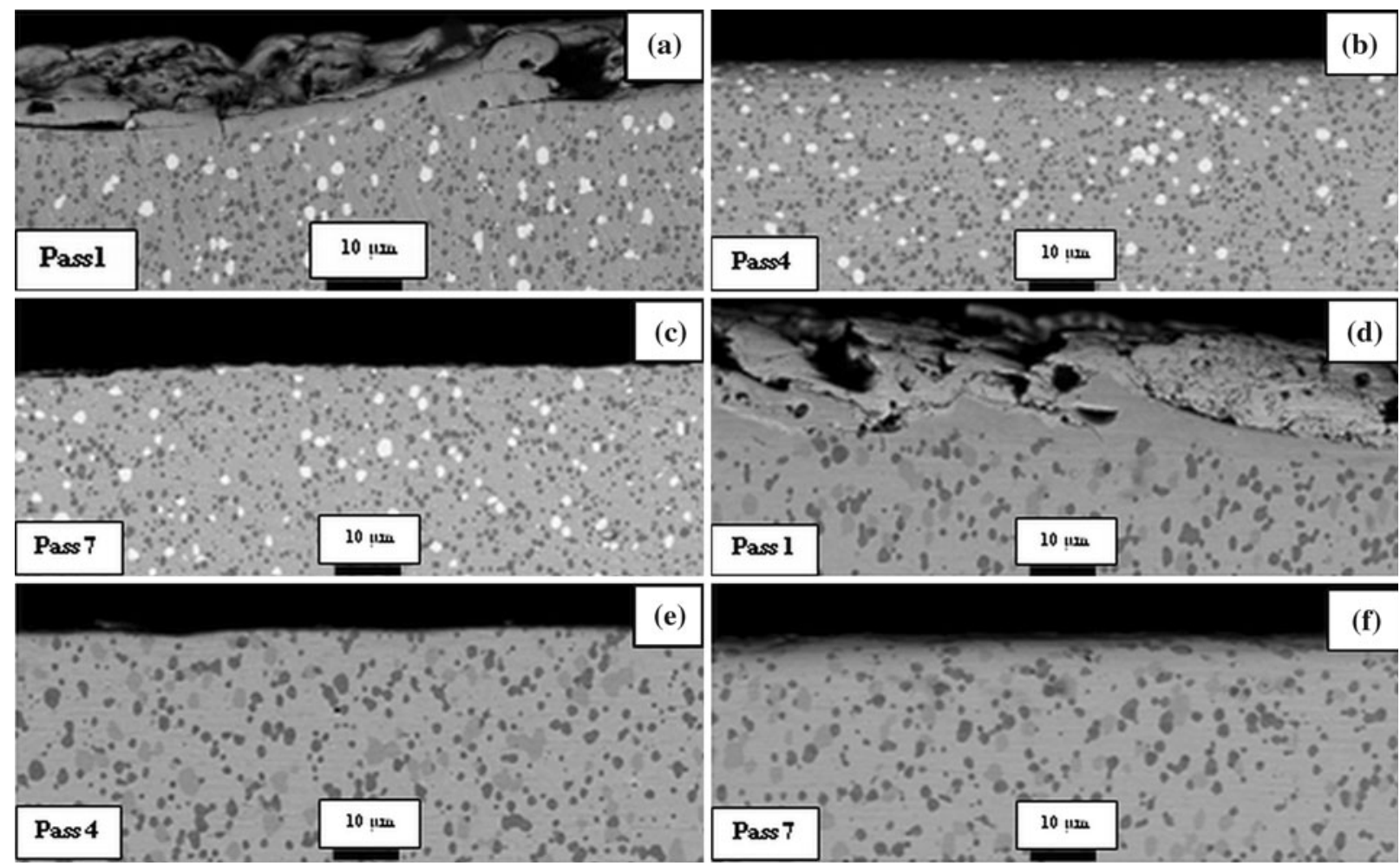

Fig. 7-SEM backscattered images of specimens cross sections: (a) through (c) Vancron 40 and (d) through (f) Vanadis 10.

\section{E. X-Ray Photoelectron Spectroscopy}

Analyses by means of XPS were carried out on the machined specimens after the first, third, and final passes (i.e., seventh pass) of WEDM. The machined surfaces were first ion $\left(\mathrm{Ar}^{+}\right)$etched corresponding to material removal of $20 \mathrm{~nm}$ in $\mathrm{Ta}_{2} \mathrm{O}_{5}$ units. Ion etching is carried out to remove the surface contamination (e.g., oxygen, carbon, hydrocarbons, etc.). Figure 11 shows the narrow scan region of the $\mathrm{Cu}-2_{\mathrm{P}}$ and $\mathrm{Zn}-2_{\mathrm{P}}$ peaks. According to XPS standard data, ${ }^{[22]} \mathrm{Cu}-2 \mathrm{P1} / 2$ and $\mathrm{Cu}-$ $2_{\mathrm{P} 3 / 2}$ peaks have binding energies of 932.4 and $952.2 \mathrm{eV}$, respectively. In addition, the binding energy of $\mathrm{Zn}-2_{\mathrm{P} 3 / 2}$ is $1021.45 \mathrm{eV} .^{[22]}$ Results from XPS analyses show peaks corresponding to $\mathrm{Cu}$ and $\mathrm{Zn}$ on both materials and on all machined surfaces. Even after the final WEDM step (i.e., seventh pass), zinc and copper are present on the surface (Figure 11).

\section{F. SEM-EDX}

In order to determine the distribution of elements throughout the recast layer, particularly the diffusion depth of copper and zinc into the work material, EDX line scans were performed. Figure 12(a) shows the cross section of a Vancron 40 grade after the first machining pass. The line across which the EDX analysis was carried out is illustrated in Figure 12(a). The distribution of elements across the line is shown in Figure 12(b). Diffusion of copper and zinc from the machined surface to a depth of $1.5 \mu \mathrm{m}$ into the material is seen in the EDX

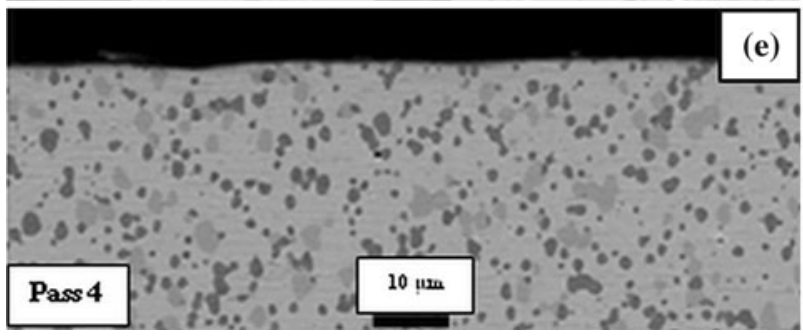



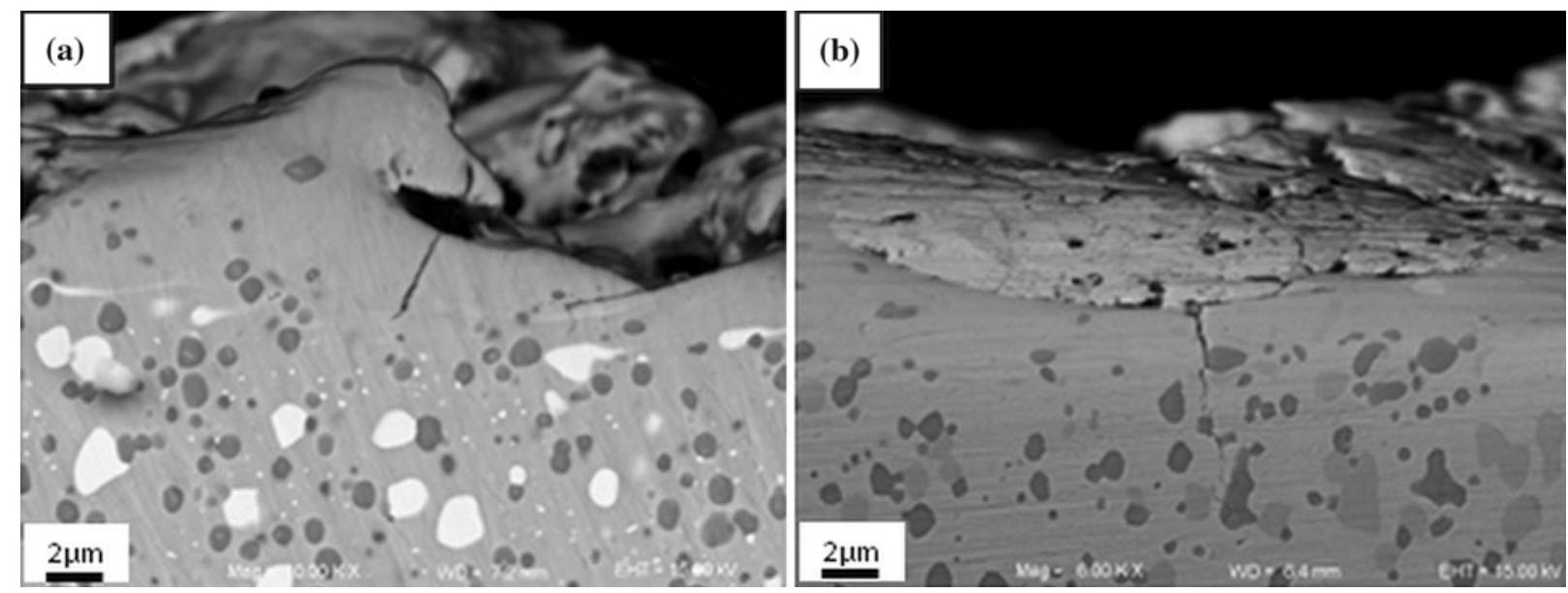

Fig. 8- SEM backscattered images of specimen cross sections after the first WEDM pass: (a) Vancron 40 and (b) Vanadis 10.

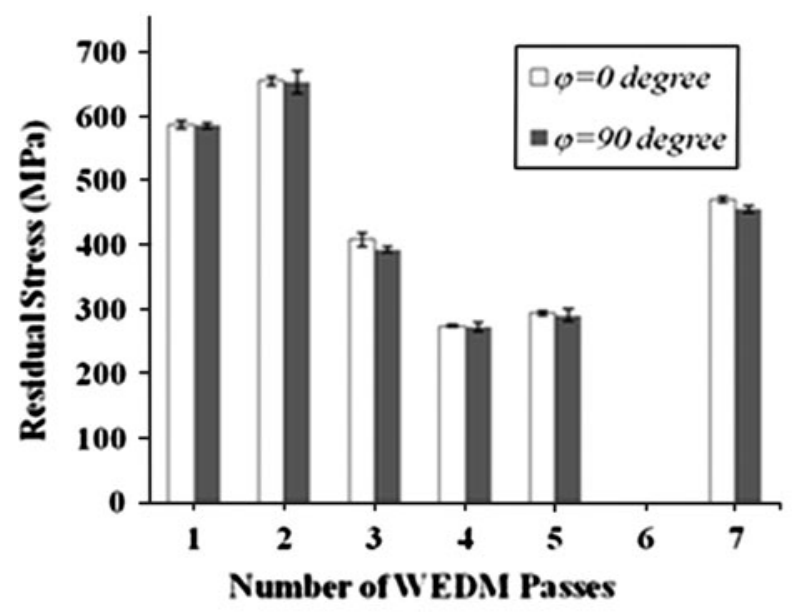

(a)

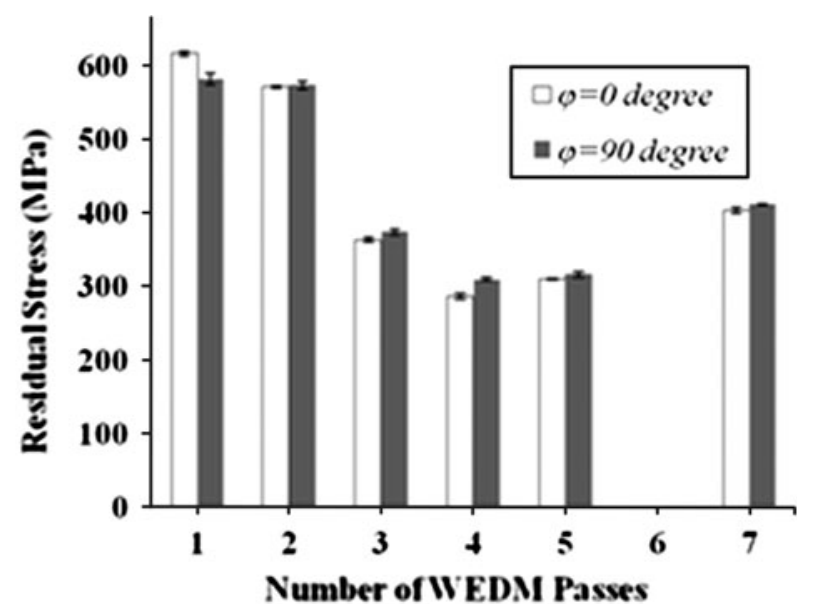

(b)

Fig. 9-Surface residual stress vs the number of WEDM passes: (a) Vancron 40 and (b) Vanadis 10. Error bars indicate the standard error of the mean.

line scan analysis (Figure 12(b)). In addition, EDX point analysis was performed at two random positions on the recast layer. The analysis shows the presence of copper and zinc (Table III).

\section{DISCUSSION}

Based on the surface topography investigation and the surface residual stress measurements, it is clear that WEDM up to four passes improves surface roughness and reduces the residual stresses (Figures 3 and 9). However, the additional WEDM steps seem to only increase the surface residual stresses, and as illustrated in Figure 9, after the final (i.e., seventh) machining pass, surface stresses are higher than after the fourth WEDM step. High tensile stresses are deleterious to the mechanical properties (particularly tensile and fatigue) as well as the dimensional accuracy of the machined component. In addition, resistance to stress corrosion cracking is reduced if the final machined surface experiences tensile stresses. The entire recast layer is removed and a smooth surface is obtained after the fourth WEDM pass (Figure 7). Hence, additional machining passes directly affect the bulk material rather than the previously formed recast layer. In other words, while the first four passes nullify the adverse effects of the previous WEDM steps, the subsequent machining passes merely negatively affect the machined surface. Thus, more than four machining steps appear to be unnecessary. Furthermore, the investigated materials are isotropic with regard to surface residual stresses.

Examination of the surface microcracks indicates that these cracks are longer and more prevalent in Vancron 40 than in Vanadis 10 (Figures 5 and 6). As illustrated in Figure 6, the crack length decreases from $\sim 3 \mathrm{~mm}$ after the first WEDM pass to $\sim 1.5 \mathrm{~mm}$ after the fourth pass. Such defects can dramatically lower the fatigue strength of these materials. No considerable reduction in crack length is achieved by performing more than four 


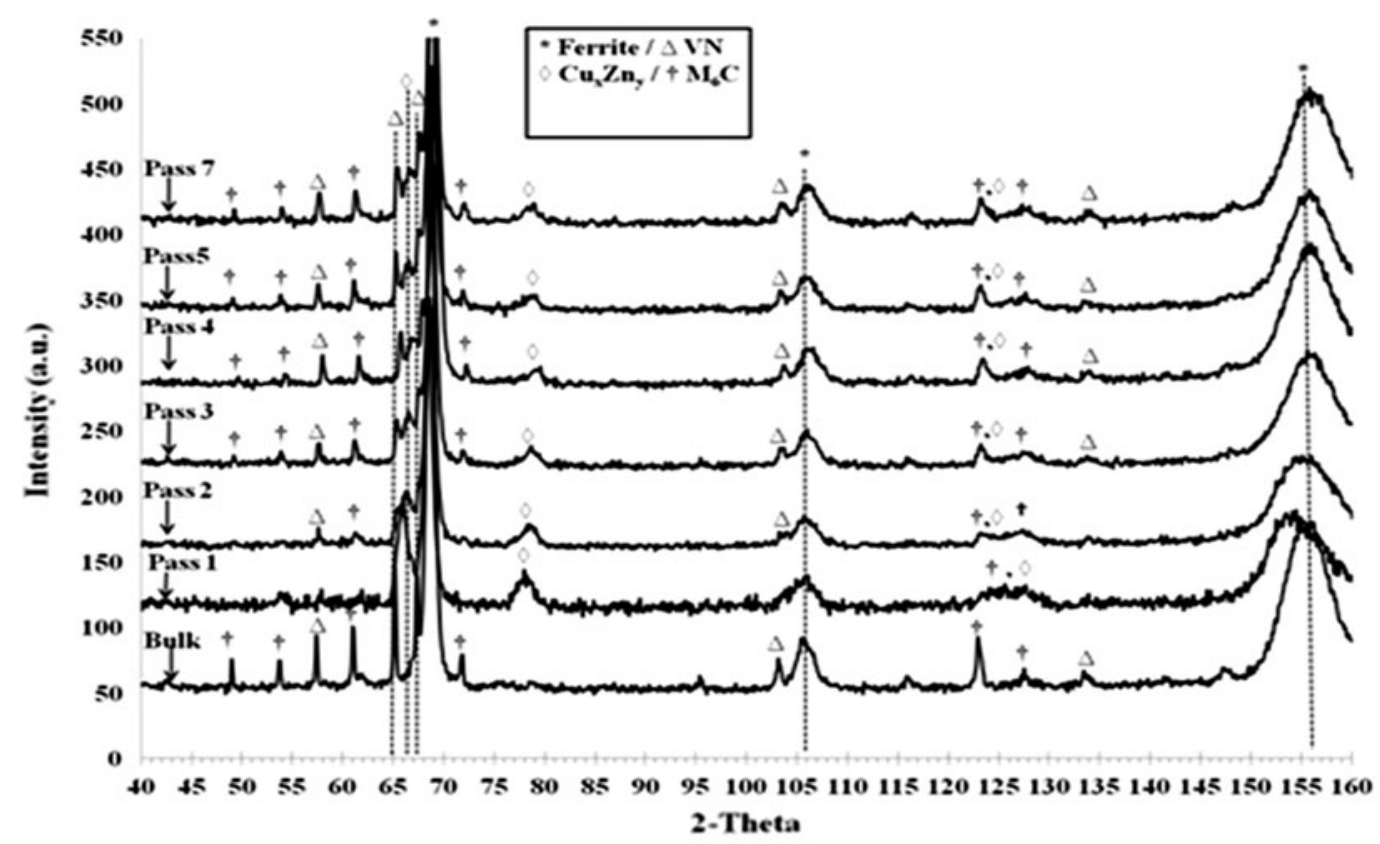

(a)

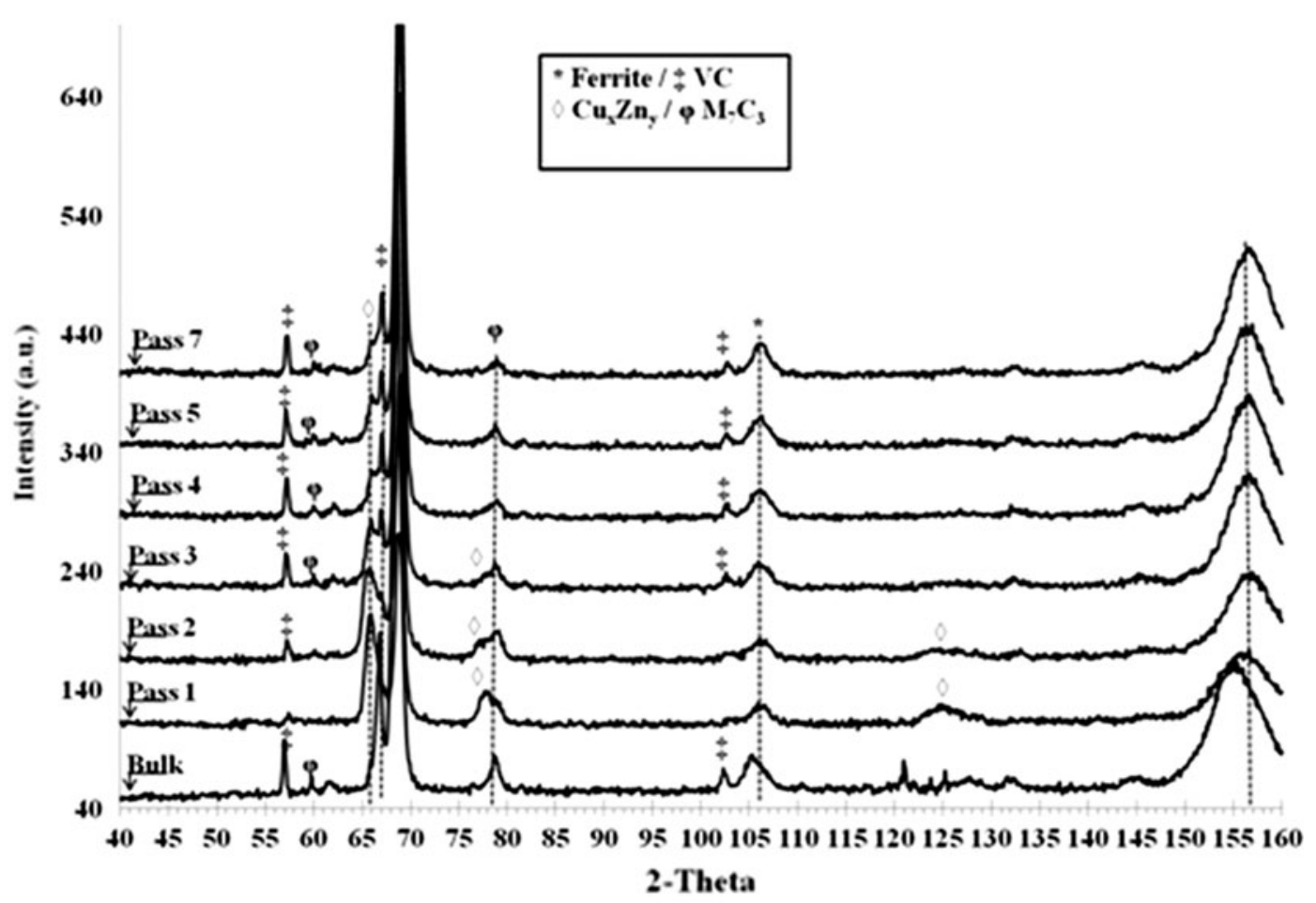

(b)

Fig. 10-XRD spectra of (a) Vancron 40 and (b) Vanadis 10.

WEDM passes (Figure 6). Generally, longer cracks are commonly found on machined surfaces with a thicker recast layer. In addition, where tensile stresses are higher, cracks tend to be longer. Hence, lengths of cracks decrease from pass 1 to pass 4 for two main reasons. First, the recast layer is being removed and becoming thinner after each pass until the fourth machining pass, after which it is almost completely removed. As a matter of fact, since the recast layer is completely removed after the fourth WEDM pass, crack length is not reduced by the subsequent machining passes (Figure 6). Second, the surface becomes smoother after every pass until the fourth pass (Figure 3). Rough surfaces tend to crack more because deep craters, voids, and remnants of resolidified molten metal will act as stress concentration points and, hence, ease cracking. 


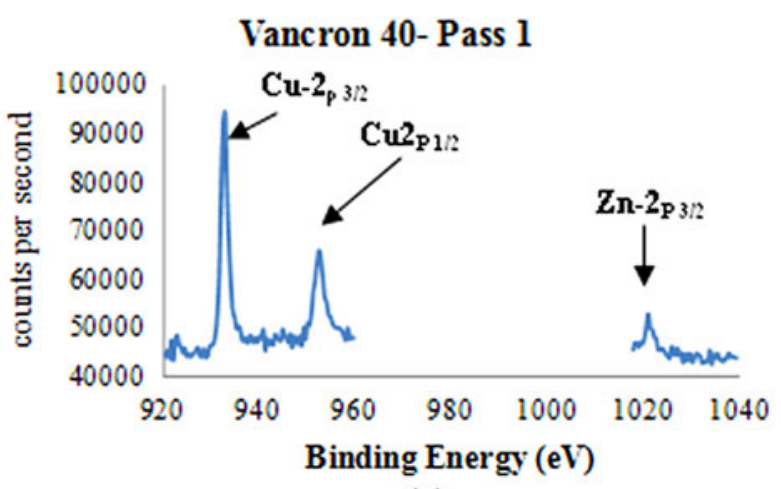

(a)

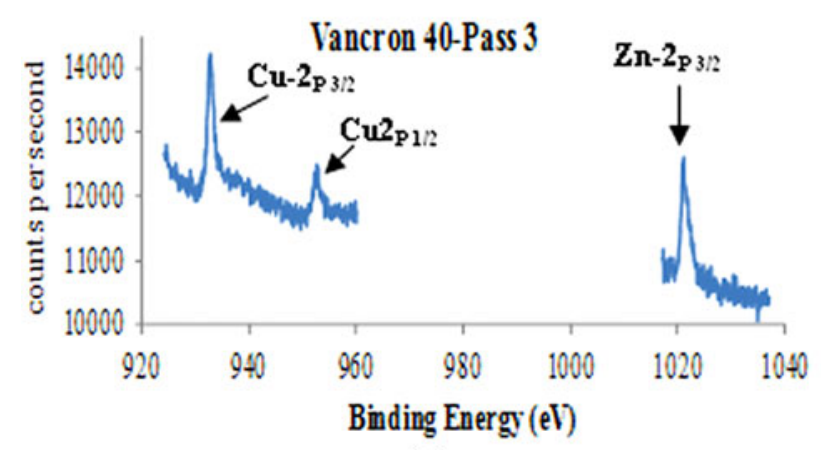

(c)

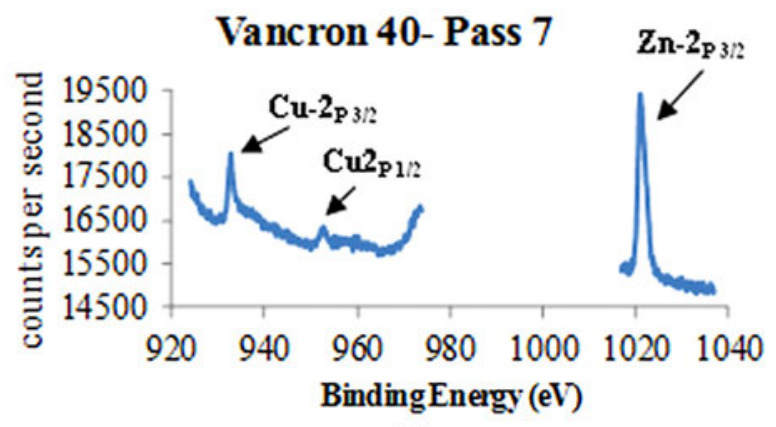

(e)

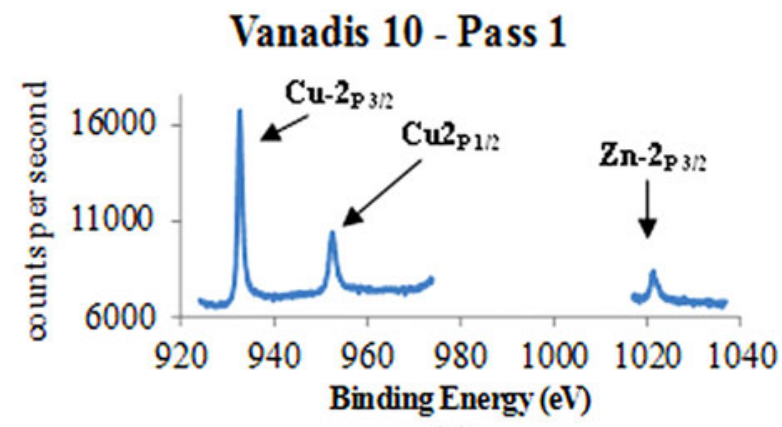

(b)

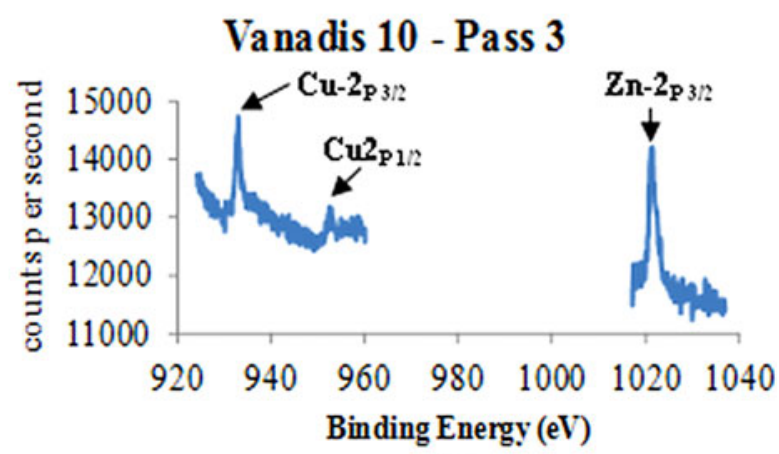

(d)

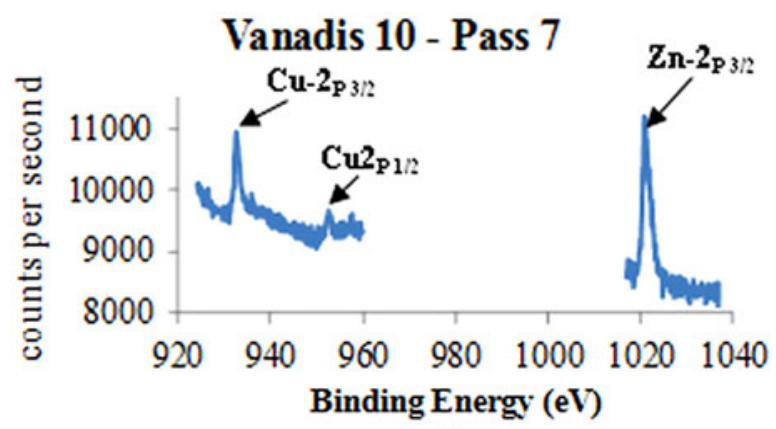

(f)

Fig. 11-Detailed XPS scans of copper and zinc (after $20 \mathrm{~nm}$ of ion etching) from the surface of the WEDM specimens. $(a)$, $(c)$, and $(e)$ Vancron 40 and $(b),(d)$, and $(f)$ Vanadis 10

Previously, it was stated that the tendency to cracking is inversely proportional to the thermal conductivity of the work material. ${ }^{[1,12,23,24]}$ This is due to the fact that the heat can dissipate faster in materials with higher thermal conductivity. ${ }^{[11]}$ However, thermal conductivity is a property that governs the flow of heat through a material in a steady-state condition, while thermal diffusivity is a material property that governs the heat flow in a transient condition. ${ }^{[25]}$ Undoubtedly, WEDM is a transient process and evaluating the thermal diffusivity of the materials is more appropriate. Basically, the latter parameter not only takes thermal conductivity into account but also includes the specific heat and the density of the material. In addition, previous researchers found that crack density increases with increasing carbon content. ${ }^{[12,13]}$ This is in contradiction to the observations made in this study, since
Vanadis 10 , which contains 2.9 wt pet carbon, shows lower tendency to cracking than Vancron 40 with $1.1 \mathrm{wt}$ pct of carbon (Figures 5 and 6).

There are two material properties that could possibly explain the higher number of cracks observed in Vancron 40 as compared to the Vanadis 10 alloy. Thermal diffusivity $(\theta)$ can be calculated based on Eq. [1]:

$$
\theta=(\lambda) /(\rho \times C p)
$$

where $\lambda$ is thermal conductivity $(\mathrm{W} / \mathrm{m} \mathrm{K}), \rho$ is density $\left(\mathrm{kg} / \mathrm{m}^{3}\right)$, and $C p$ is specific heat $(\mathrm{J} / \mathrm{kg} \mathrm{K})$. Thermal shock resistance is the ability of the material to withstand any sort of weakening (e.g., cracking, yielding, buckling, and spalling) when exposed to thermal stresses. The stress $(\Delta \sigma)$ caused by a rapid temperature 

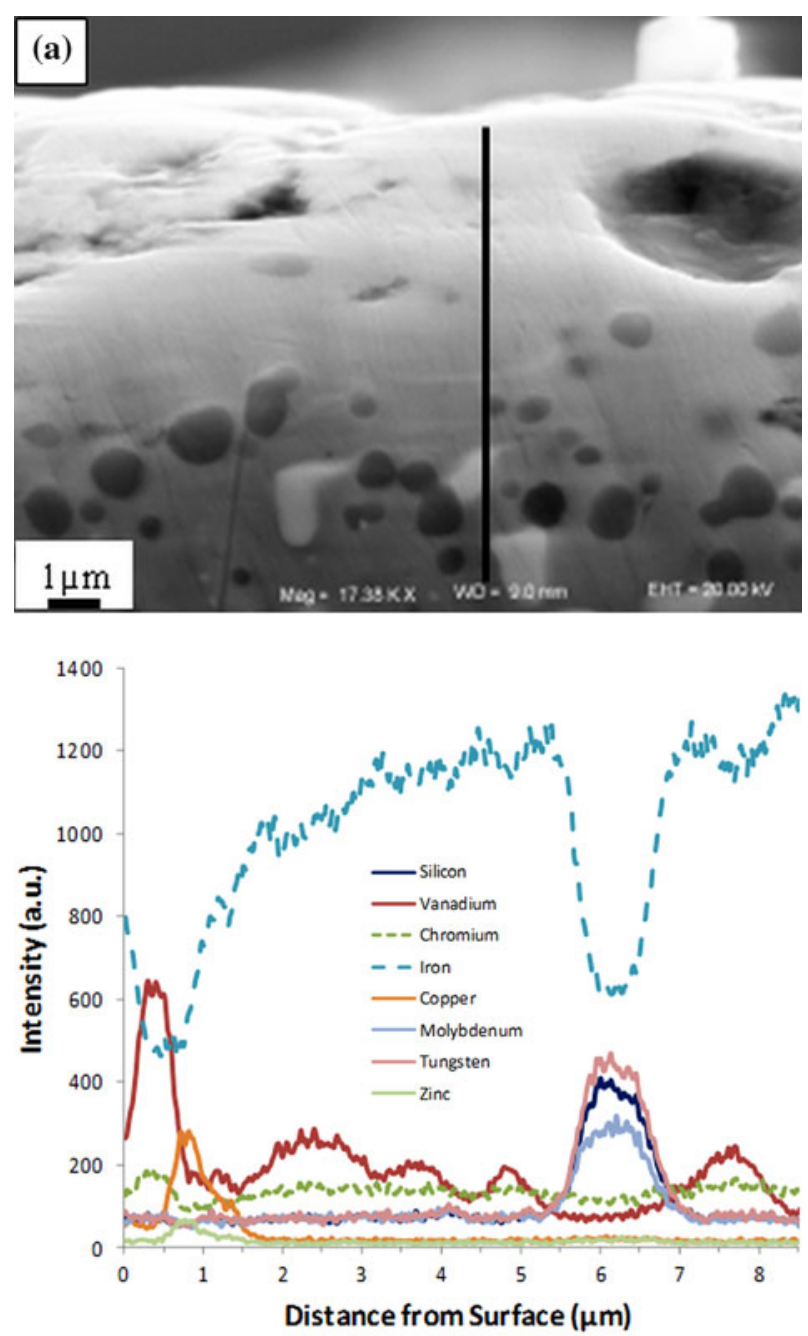

(b)

Fig. 12-(a) SEM image of the cross section of a Vancron 40 grade after the first WEDM pass. EDX analysis was performed across the black line. (b) Distribution of elements across the line. (For interpretation of the references to color in this figure, the reader is referred to the web version of the article.) change of $1 \mathrm{~K}$ at the surface of a material is given by $^{[25]}$

$$
(C \times \Delta \sigma)=(\alpha \times E)
$$

where $C$ is a parameter determining the way in which the material is constrained. For example, for axial constraint, $C$ is equal to 1 , and for biaxial constraint or normal quenching, $C$ is equal to $(1-v) ; v$ is the Poisson's ratio. ${ }^{[25]}$ The other parameters in Eq. [2] are $\alpha$, which is the linear thermal coefficient of expansion, and $E$, which is the Young's Modulus. The physical and mechanical properties of the alloys are given in Table IV. Based on the data inset in Table IV, and using Eqs. [1] and [2], the thermal diffusivity and thermal stress (caused by a rapid temperature change of $1 \mathrm{~K}$ ) are calculated (Table IV).

As shown in Table IV, it is clear that while there is no significant difference in the thermal diffusivity of both materials, the difference in thermal stresses $(\Delta \sigma)$ developed per $1 \mathrm{~K}$ change in temperature is considerable. To realize this considerable discrepancy, assume that the work material is experiencing a rapid temperature change of $\Delta T=1000 \mathrm{~K}$. In other words, the material has been cooled from $1473 \mathrm{~K}$ to $473 \mathrm{~K}\left(1200{ }^{\circ} \mathrm{C}\right.$ to $\left.200{ }^{\circ} \mathrm{C}\right)$. The thermal stress induced as a result of this temperature change can be calculated according to Eq. [3].

$$
\sigma=(E \times \alpha \times \Delta T) / C
$$

By inserting the data given in Table IV into Eq. [3], the induced stress is calculated to be 3499 and $3036 \mathrm{MPa}$ for Vancron 40 and Vanadis 10 alloys, respectively. The calculations show that thermal stresses generated in Vancron 40 are higher than that in Vanadis 10. Undoubtedly, thermal stresses are amplified even further by the presence of surface defects (e.g., porosity, protrusions, and craters), since these defects act as stress concentration points.

If the exerted thermal stress is greater than the tensile strength of the material $(\sigma t)$, cracking will occur. Hence, an approximate measure of thermal shock resistance is given by ${ }^{[25]}$

Table III. EDX Point Analysis Performed on the Re-Cast Layer of Vancron 40 Alloy after the First WEDM Pass; Composition is in Weight Percent

\begin{tabular}{lccccccccc}
\hline Vancron 40 & $\mathrm{Si}$ & $\mathrm{V}$ & $\mathrm{Cr}$ & $\mathrm{Mn}$ & $\mathrm{Fe}$ & $\mathrm{Cu}$ & $\mathrm{Zn}$ & Mo & W \\
\hline Point 1 & 0.93 & 8.26 & 4.19 & 0.29 & 68.83 & $\underline{7.59}$ & $\underline{1.88}$ & 3.69 & 4.33 \\
Point 2 & 0.90 & 7.18 & 3.91 & 0.33 & 64.59 & $\underline{12.86}$ & $\underline{2.97}$ & 3.36 & 3.90 \\
\hline
\end{tabular}

Table IV. Physical and Mechanical Properties of the Investigated Alloys at $473 \mathrm{~K}\left(200{ }^{\circ} \mathrm{C}\right)$; Thermal Stress $(\Delta \sigma)$ and Thermal

\begin{tabular}{|c|c|c|c|c|c|c|c|c|}
\hline Material & $\lambda(\mathrm{W} / \mathrm{m} \mathrm{K})$ & $\rho\left(\mathrm{kg} / \mathrm{m}^{3}\right)$ & $C p(\mathrm{~J} / \mathrm{kg} \mathrm{K})$ & $\alpha 10^{-6}\left(\mathrm{~K}^{-1}\right)$ & $E(\mathrm{MPa})$ & $v$ & $\Delta \sigma(\mathrm{MPa} / \mathrm{K})$ & $\Theta\left(\mathrm{m}^{2} / \mathrm{s}\right)$ \\
\hline Vancron 40 & $21 *$ & $7680^{\dagger}$ & $540^{\dagger}$ & $11.1 *$ & 227,000 * & $0.28^{\dagger}$ & 3.49 & $5.06 \times 10^{-6}$ \\
\hline Vanadis 10 & $20 * *$ & $7500^{\dagger}$ & $540^{\dagger}$ & $10.7 * *$ & $210,000 * *$ & $0.26^{\dagger}$ & 3.03 & $4.09 \times 10^{-6}$ \\
\hline
\end{tabular}
Diffusivity $(\theta)$ are Calculated 
Table V. Simulated Tensile Strength at $473 \mathrm{~K}\left(200{ }^{\circ} \mathrm{C}\right)$ and the Calculated Thermal Shock Resistance of the Investigated Alloys

\begin{tabular}{lcc}
\hline Material & $\sigma t(\mathrm{MPa})$ & $\begin{array}{c}\text { Thermal Shock } \\
\text { Resistance }\end{array}$ \\
\hline Vancron 40 & 2964 & 1176 \\
Vanadis 10 & 2961 & 1317 \\
\hline
\end{tabular}

$$
\Delta T / C=\sigma t /(\alpha \times E)
$$

To be able to rank Vancron 40 and Vanadis 10 materials according to their thermal shock resistance, the true stress-true strain curve of both alloys was simulated at $473 \mathrm{~K}\left(200{ }^{\circ} \mathrm{C}\right)$. The simulations were performed using the material simulation software JMatPro (6.0) (Sente Software Ltd., Guildford, Surrey, United Kingdom). ${ }^{[28]}$ For these simulations, besides the chemical compositions of the alloys, hardness (62 HRC) and austenite grain size $(80 \mu \mathrm{m})$ were taken into consideration. The austenite grain size was estimated based on the following formula, which is used in JMatPro software:

$$
D^{a}=C \times t \times \exp (-Q / \mathrm{RT})
$$

where grain size (D) is in millimeters, $a$ and $C$ are the material constants, $Q$ is the activation energy, $\mathrm{R}$ is the gas constant, and $T$ is the temperature in Kelvin. The values a $=4, C=0.4948 \times 10^{14} \mathrm{~mm}^{4} / \mathrm{s}$, and $Q / \mathrm{R}=$ 63,900 are recommended by the software. By inserting the austenitization time ( 0.5 hours) and temperature (1293 K) of the investigated alloys (according to Table II) in Eq. [5], D can be calculated.

The simulated tensile strength and the calculated thermal shock resistance are given in Table V. As shown in Table V, Vanadis 10 grade has a higher thermal shock resistance than Vancron 40. This is most likely the reason why fewer cracks are found in Vanadis 10 as compared to Vancron 40.

In the XRD spectra corresponding to the first and second machining passes (Figure 10), peaks associated with precipitates (primary and secondary hard particles) are either absent or very weak. This suggests that the material was rapidly cooled from the molten state to room temperature. The cooling rate was fast enough to prevent precipitation of the primary and secondary carbides/nitrides. Huang et al. ${ }^{[29]}$ reports a similar observation when machining a martensitic stainless steel by WEDM. Hence, the carbide and nitride forming elements (V, W, Mo, Mn, and $\mathrm{Cr}$ ) as well as carbon and nitrogen are all in solid solution. It is important to note that among the alloying elements existing in the investigated steel grades, vanadium, tungsten, molybdenum, chromium, and silicon are ferrite stabilizers, whereas carbon, nitrogen, and manganese are austenite formers. ${ }^{[30]}$ Therefore, obviously, after the first and second passes of WEDM, the machined surfaces are not only undesirable in terms of residual stresses, surface roughness, and surface defects, but also in terms of distribution of alloying elements and, in turn, microstructure.
The reappearance of XRD peaks associated with the primary and secondary hard phases from the second WEDM pass onward is due to the fact that the recast layer was almost completely removed after the second pass. In other words, the machined surfaces after the third pass start to resemble the bulk material. Consequently, XRD patterns of the machined surfaces after the third pass resemble that of the bulk material.

Characterization of the machined surfaces by means of XRD, SEM-EDX, and XPS reveals the existence of $\mathrm{Cu}$ and $\mathrm{Zn}$ on the machined surfaces (on both tool steel grades) and even after the final WEDM step. The XPS results, illustrated in Figure 11, show that the copper to zinc peak ratio is higher in the first WEDM passes as compared to the final WEDM steps. In other words, the concentration of copper is higher in the initial WEDM cuts, and it decreases by increasing the number of WEDM steps. Regarding zinc, the opposite trend is seen. Both $\mathrm{Cu}$ and $\mathrm{Zn}$ have diffused from the wire electrode (which was a brass wire coated with zinc) into the work material. This alloying phenomenon is due to the positive polarity of the electrode during the machining operations. When positive polarity is used, most of the heat is generated at the electrode, and hence, elements from the wire electrode can diffuse into the work material. ${ }^{[18,29]}$ Moreover, insufficient flush pressure could also be responsible for alloying by the wire electrode, since the medium will not be able to wash away the existing $\mathrm{Cu}$ and $\mathrm{Zn}$ on the work material. ${ }^{[29]} \mathrm{In}$ this study, the influence of $\mathrm{Cu}$ and $\mathrm{Zn}$ on the performance of these tool steels was not investigated; however, it is well known that the addition of copper into steel leads to hot shortness and surface cracking at around $1373 \mathrm{~K}\left(1100^{\circ} \mathrm{C}\right) \cdot .^{[31]}$

\section{CONCLUSIONS}

Surface preparation of two newly developed PM tool steels by means of WEDM was investigated. Multicutting WEDM was carried out up to seven passes. It was found that surface roughness and surface residual stresses were lowered by the first four WEDM passes; however, further machining steps did not bring any considerable improvements. Thermal shock resistance of both alloys was calculated. The higher cracking tendency of Vancron 40 as compared to Vanadis 10 was attributed to the former's lower thermal shock resistance. Characterization of the recast layer after every WEDM step indicated diffusion of $\mathrm{Cu}$ and $\mathrm{Zn}$ from the wire electrode into the work material.

Finally, it can be concluded that although multicutting WEDM is, in principle, capable of improving the surface integrity of the investigated tool steels, an excessive number of machining steps can adversely affect the performance of the material and will only increase its processing costs. Despite the fact that the ultimate goal of most tool makers is producing mirrorlike surfaces, the number of WEDM passes should be chosen wisely, based on the requirements of the forming operation and while taking into account the gain in surface integrity after each machining step. In general, 
this study shows that for the investigated tool steels, a WEDM procedure including four passes seems to be sufficient and effective in enhancing the surface integrity.

\section{ACKNOWLEDGMENTS}

The authors thank the financial support from the Swedish Foundation for Strategic Research (SSF) and The Foundation for Strategic Environmental Research (MISTRA) through the ProEnviro research program. In addition, Uddeholms AB (Hagfors, Sweden) is acknowledged for supply of materials and technical support. The following staff members of the Department of Materials and Manufacturing Technology (Chalmers University of Technology) are thanked for their technical assistance: Messrs. Seyed B. Hosseini, Urban Jelvestam, Pouya Habibzadeh, and Seshendra Karamchedu.

\section{REFERENCES}

1. O. Sandberg and L. Westin: U.S. Patent No. 6,818,040 B1, 2004.

2. S. Hatami, L. Nyborg, and J.O. Krona: 2008 World Congr. on Powder Metallurgy and Particulate Materials, Washington, DC, 2008, MPIF, Princeton, NJ, 2008, pp. 104-18.

3. S. Hatami, A. Nafari, L. Nyborg, and U. Jelvestam: Wear, 2010, vol. 269 , pp. $229-40$.

4. O. Sandberg: EURO PM2004, Vienna, Austria, 2004, EPMA, Shrewsbury, United Kingdom, 2004, vol. 3, pp. 706-12.

5. O. Sandberg: 7th Int. Tooling Conf., Torino, Italy, 2006, Politecnico di Torino, Torino, 2006, pp. 13-20.

6. O. Sandberg: Tool 09, Aachen, Germany, 2009, RWTH Aachen University, Aachen, 2009, vol. 1, pp. 357-67.

7. B. Ekmekci, O. Elkoca, and A. Erden: Metall. Mater. Trans. B, 2005, vol. 36B, pp. 117-24.

8. L.C. Lim, L.C. Lim, Y.S. Wong, and H.H. Lu: Mater. Sci. Technol., 1991, vol. 7, pp. 239-48.

9. B. Ekmekci: Appl. Surf. Sci., 2007, vol. 253, pp. 9234-40.

10. M. Barash: Int. J. Mach. Tool Des. Res., 1962, vol. 2, pp. 331-95.
11. Y.S. Wong, L.C. Lim, and L.C. Lee: J. Mater. Process. Technol., 1995, vol. 48, pp. 299-305.

12. L.C. Lee, L.C. Lim, and Y.S. Wong: J. Mater. Process. Technol., 1992, vol. 32, pp. 45-54.

13. L.C. Lee, L.C. Lim, and Y.S. Wong: J. Mater. Process. Technol., 1992, vol. 29, pp. 213-21.

14. S.H. Kang and D.E. Kim: Mater. Sci. Technol., 2005, vol. 21, pp. $817-23$.

15. H.K. Lloyd and R.H. Warren: J. Iron Steel Inst., 1965, vol. 203, pp. 238-47.

16. H.T. Lee, F.C. Hsu, and T.Y. Tai: Mater. Sci. Eng. A, 2004, vol. 364 A, pp. $346-56$.

17. M.A.E.-R. Merdan and R.D. Arnell: Surf. Eng., 1989, vol. 5, pp. $158-64$.

18. J.E. Fuller: ASM Handbook, vol. 16, Electrical Discharge Machining, ASM INTERNATIONAL, Metals Park, OH, 1997.

19. K. Frisk, G. Lindwall, N. Olsson, O. Sandberg, and I. Siller: Tool 09, Aachen, Germany, 2009, RWTH Aachen University, Aachen, 2009, pp. 727-36.

20. M.E. Fitzpatrick, A.T. Fry, P. Holdway, F.A. Kandil, J. Shackleton, and L. Suominen: Measurement Good Practice Guide 52, National Physical Laboratory, Teddington, Middlesex, United Kingdom, 2005, pp. 5-11.

21. E.W.K. Honeycombe: Structure and Strength of Alloy Steels, 1st ed., Climax Molybdenum, London, 1973.

22. C.D. Wagner, W.M. Riggs, L.E. Davis, J.F. Moulder, and G.E. Muilenberg: Handbook of X-Ray Photoelectron Spectroscopy, Perkin-Elmer Co., Eden Prairie, MN, 1979.

23. E. Lenz, W. Koenig, R. Wertheim, and E. Katz: Ann. CIRP, 1975, vol. 24, pp. 109-14.

24. L.C. Lee, L.C. Lim, Y. Narayanan, and V.C. Venkatesh: Int. J. Mach. Tool Manuf., 1988, vol. 28, pp. 359-72.

25. M.F. Ashby: Materials Selection in Mechanical Design, 2nd ed., Butterworth Heinemann, Oxford, United Kingdom, 2003, pp. 4756.

26. Uddeholms AB: http://www.uddeholm.com/files/PB_vancron_40_ english.pdf, 2011.

27. Uddeholms AB: http://www.uddeholm.com/files/PB_vanadis_ 10_english.pdf, 2011.

28. JMatPro: http://www.sentesoftware.co.uk/jmatpro.aspx, 2011.

29. C.A. Huang, F.Y. Hsu, and S.J. Yao: Mater. Sci. Eng. A, 2004, vol. 371A, pp. 119-26.

30. K.W. Andrews: J. Iron Steel Inst., 1956, pp. 414-27.

31. G Krauss: Steels-Processing, Structure, and Performance, 2nd ed., ASM INTERNATIONAL, Materials Park, OH, 2005, pp. 38587. 